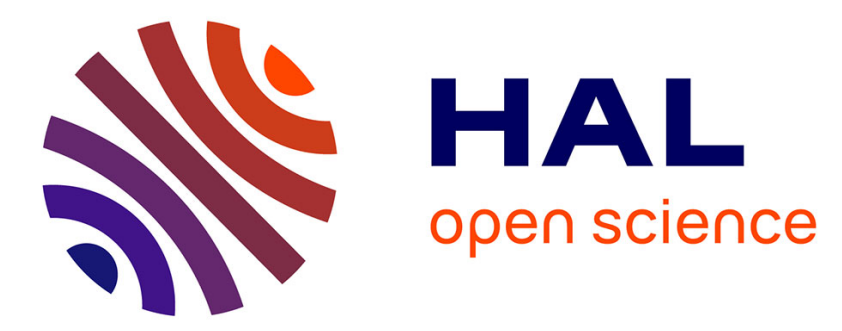

\title{
Evidence of two distinct phylogenetic lineages of dog rabies virus circulating in Cambodia.
}

Channa Mey, Artem Metlin, Veasna Duong, Sivuth Ong, Sotheary In, Paul F

Horwood, Jean-Marc Reynes, Hervé Bourhy, Arnaud Tarantola, Philippe Buchy

\section{To cite this version:}

Channa Mey, Artem Metlin, Veasna Duong, Sivuth Ong, Sotheary In, et al.. Evidence of two distinct phylogenetic lineages of dog rabies virus circulating in Cambodia.. Infection, Genetics and Evolution, 2016, 38, pp.55-61. 10.1016/j.meegid.2015.12.011 . pasteur-01429885

\section{HAL Id: pasteur-01429885}

\section{https://hal-pasteur.archives-ouvertes.fr/pasteur-01429885}

Submitted on 9 Jan 2017

HAL is a multi-disciplinary open access archive for the deposit and dissemination of scientific research documents, whether they are published or not. The documents may come from teaching and research institutions in France or abroad, or from public or private research centers.
L'archive ouverte pluridisciplinaire HAL, est destinée au dépôt et à la diffusion de documents scientifiques de niveau recherche, publiés ou non, émanant des établissements d'enseignement et de recherche français ou étrangers, des laboratoires publics ou privés.

\section{(c)(1)}

Distributed under a Creative Commons Attribution| 4.0 International License 
TITLE: Evidence of two distinct phylogenetic lineages of dog rabies virus circulating in Cambodia

SHORT TITLE: Phylogeny of rabies virus in Cambodia

CONTENTS CATEGORY: Standard (full-length) paper

AUTHORS: Channa Mey ${ }^{1 \#}$, Artem Metlin ${ }^{1 \#}$, Veasna Duong ${ }^{1}$, Sivuth Ong ${ }^{1}$, Sotheary In $^{2}$, Paul F. Horwood $^{1}$, Jean-Marc Reynes ${ }^{3}$, Hervé Bourhy ${ }^{4}$, Arnaud Tarantola ${ }^{5}$, Philippe Buchy ${ }^{1,6^{*}}$

${ }^{1}$ Virology Unit, Institut Pasteur in Cambodia

${ }^{2}$ Rabies Prevention Center, Institut Pasteur in Cambodia

${ }^{3}$ Unité de Biologie des Infections Virales Emergentes, Institut Pasteur. Centre International de Recherche en Infectiologie, Lyon, France

${ }^{4}$ Institut Pasteur, Unit Lyssavirus Dynamics and Host Adaptation, WHO Collaborative Centre for Reference and Research on Rabies, Paris, France

${ }^{5}$ Epidemiology and Public Health Unit, Institut Pasteur in Cambodia

${ }^{6}$ GlaxoSmithKline Vaccines R\&D, 150 Beach Road, Singapore

\section{* Corresponding author}

\#these authors contributed equally

HOST LABORATORY: Virology Unit, Institut Pasteur in Cambodia 5, Monivong Blvd - PO Box 983 Phnom Penh, Cambodia.

CORRESPONDING AUTHOR'S ADDRESS: Institut Pasteur in Cambodia, Virology Unit, 5 Monivong blvd, Phnom Penh, Cambodia - GlaxoSmithKline, Vaccines R\&D, 150 Beach Road, Singapore. Email: buchyphilippe@hotmail.com 


\section{Summary}

This first extensive retrospective study of the molecular epidemiology of dog rabies in Cambodia included 149 rabies virus (RABV) entire nucleoprotein sequences obtained from 1998-2011. The sequences were analyzed in conjunction with RABVs from other Asian countries. Phylogenetic reconstruction confirmed the South-East Asian phylogenetic clade comprising viruses from Cambodia, Vietnam, Thailand, Laos and Myanmar. The present study represents the first attempt to classify the phylogenetic lineages inside this clade, resulting in the confirmation that all the Cambodian viruses belonged to the South-East Asian (SEA) clade. Three distinct phylogenetic lineages in the region were established with the majority of viruses from Cambodia closely related to viruses from Thailand, Laos and Vietnam, forming the geographically widespread phylogenetic lineage SEA1. A South-East Asian lineage SEA2 comprised two viruses from Cambodia was identified, which shared a common ancestor with RABVs originating from Laos. Viruses from Myanmar formed separate phylogenetic lineages within the major SEA clade. Bayesian molecular clock analysis suggested that the time to most recent common ancestor (TMRCA) of all Cambodian RABVs dated to around 1950. The TMRCA of the Cambodian SEA1 lineage was around 1964 and that of the SEA2 lineage was around 1953. The results identified three phylogenetically distinct and geographically separated lineages inside the earlier identified major SEA clade, covering at least five countries in the region. A greater understanding of the molecular epidemiology of rabies in South-East Asia is an important step to monitor progress on the efforts to control canine rabies in the region.

\section{Highlights:}

We performed the first extensive rabies virus evolutionary study in Cambodia;

We generated and analyzed 149 Cambodian rabies virus nucleoprotein sequences;

We identified 3 phylogenetic lineages in the major South-East Asian clade.

Key words: rabies virus evolution, rabies epidemiology, canine rabies, Cambodia, South-East Asia 


\section{Introduction}

The developing world is severely affected by rabies, causing deaths in humans as well as in animals and resulting in significant economic losses. Indeed, it is estimated that globally canine rabies causes approximately 59,000 human deaths, over 3.7 million disability-adjusted life years (DALYs) and 8.6 billion USD in economic losses annually (Hampson et al., 2015).

Rabies virus (RABV) belongs to the family Rhabdoviridae of the order Mononegavirales which comprises at least 10 genera (http://www.ictvonline.org). The Lyssavirus genus includes classical RABVs, found in a wide range of different animal species throughout the world. All 13 other species of Lyssavirus except two have been isolated from bats, originating from different locations in Europe, Asia, Africa and Australia. RABV has a negative-sense RNA genome of about $12 \mathrm{~kb}$ encoding five proteins (Tordo et al., 1986, 1993). The nucleoprotein gene (N-gene) is widely used for molecular characterization and phylogenetic analysis of RABVs (Kissi et al., 1995). The large number of N-gene sequences published makes this an obvious region of the genome to study (Johnson et al., 2002, Chupin et al., 2013). The N-gene is also suitable for estimations of evolutionary rate and subsequent analysis of evolutionary history (Holmes et al., 2002; Bourhy et al., 2008).

Most South-East Asian countries are affected by rabies, but with the exception of a few countries, there is limited accurate epidemiological information available. According to the World Organization for Animal Health (OIE), there were 15 animal rabies outbreaks recorded in Vietnam in 2012 with 86 rabies cases found in dogs in five different administrative divisions of the country. For Laos it was only mentioned that rabies was present in 2012 with no indication of the number of outbreaks/cases. In Myanmar, the number of human rabies cases per year was estimated at about 1000 while in Thailand it was less than 25 (Gongal \& Wright, 2011).

The only reliable data on human and animal rabies in Cambodia are available from the Institut Pasteur in Cambodia (IPC) where rabies diagnosis activity has been performed routinely since 1998, but laboratory-confirmed cases of rabies in dogs were recorded since the 1970s (Reynes et al., 1999). In the second half of the 1970s, dogs which are the most important vector for human rabies in Asia (Dodet et al., 2001) almost disappeared from Cambodia because of starvation. However, dog numbers rebounded in subsequent decades and rabies consequently became a serious public health concern. During the mid1980s, the number of patients who have sought medical assistance after a dog bite has been at least 4000 per year, but the number of reported rabies deaths has been very low, partly because of improved postexposure treatment delivery. Deaths occurring at home are usually not reported to health services. From 
1982 to 1991 a total of 5437 animal bites were recorded and 51 human rabies deaths were reported (WHO/Rab. Res./93.44). Since 1994, rabies stopped being a notifiable disease in Cambodia. Thus, the only data available after 1994 is from the IPC, which established a rabies post-exposure treatment centre in 1995 (Reynes et al., 1999). From mid-1995 to 2007, 149,224 post-exposure prophylaxis (PEP) treatments were provided at the IPC Rabies Prevention Centre (Reynes, 1999; Ly, 2009; $\mathrm{WHO} / \mathrm{EMC} / \mathrm{ZOO} / 96.8$ ) and still 67 fatal human cases were reported countrywide following dog bites.

During 1998-2007, 610 animal samples (49\% of all specimens tested) originating mostly from dogs with suspected rabies were found rabies-positive (Ly et al., 2009). A predictive model established by Ly et al. (2009) estimated that 810 human rabies cases occurred in 2007 alone. In 2008-2013, rabies was recorded mostly in dogs $(n=932,99.3 \%)$. Rabies cases in cats $(n=3,0.3 \%)$, bovines $(n=3,0.3 \%)$ and swine ( $\mathrm{n}=1,0.1 \%)$ were detected in very rare occasions (Institut Pasteur in Cambodia, unpublished data).

At present, the dog population in Cambodia is estimated to exceed 5 million animals and nearly one-third of the 250 Cambodian households surveyed in a preliminary study could recall at least one dog bite experience during 2004-2009 (Institut Pasteur in Cambodia, unpublished). Overall, the risk proportion (total number dog bites/total human population) in Cambodia was 5.6\% (75/1339). This equates to an annual incidence of 1120 dog bites per 100000 people (Lunney et al., 2012). Other mammals like mongoose, bats or other wild animals are sometimes suspected in Asia to contribute to maintaining the circulation of rabies. In Cambodia, Reynes et al. (2004) found serological evidence of Lyssavirus infection in bats. Several studies on RABV molecular epidemiology in Asia (Bourhy et al., 2008), namely in Vietnam (Nguyen et al., 2011; Yamagata et al., 2007), Thailand (Ito et al., 1999) and Laos (Ahmed et al., 2015) were conducted previously.

The objective of the present study was to perform a retrospective molecular and phylogenetic characterization of RABVs from dogs originating from different parts of Cambodia, to compare them to strains originating from other South-East Asian countries and to analyze the circulation of dog RABVs in this region.

\section{Materials and Methods}

2.1. Samples and Viruses. Dog brain samples received by the IPC Virology Unit from different regions of Cambodia between 1998 and 2011 were included in the study. In total, 149 rabies-positive samples obtained from dogs originating from 20 administrative regions of Cambodia were selected by location and year of sampling (Supplementary Table 1). Dog's heads were usually referred to the IPC lab 
from people who were consulting for PEP following the animal bite. The animal samples were tested by a standard direct fluorescent antibody test (FAT) (Dean et al., 1996) using an anti-rabies nucleocapsid conjugate (Anti-Rabies Nucleocapsid Conjugate; lyophilizied, adsorbed \#357-2112, Bio-Rad, Marnesla-Coquette, France) according to the manufacturer's instructions.

2.2. RNA purification, Reverse Transcriptase PCR and Nucleotide Sequencing. The diagnostic method for the initial detection of the RABV from clinical samples used a hemi-nested RT-PCR targeting a conserved region of the L-gene to confirm results of FAT as previously published (Dacheux et al., 2008). The target size of amplicons obtained after the second round of PCR was approximately 250 base pairs. Negative and positive control samples were included successively for each extraction, reverse transcription, and for all PCR steps.

To generate amplicons for sequence analysis, two overlapping RT-PCRs were conducted targeting the N-gene (Yang et al., 2011), which has been extensively used for phylogenetic analyses of RABVs. The two sequencing PCRs (Table 1) were conducted using the same reaction conditions and cycling protocols as previously described (Dacheux et al., 2008). The first PCR, using the primers RVN71F (5'-ATGGATGCCGACAAGATTGTATTC-3') and RVN-1118R (5'GAATTCCTCTCCCAGATAGCC-3') generated a 1048 bp amplicon; the second PCR, using the primers RVN-1091F (5'-CTAGGGGGCTATCTGGGAGA-3') and RVN-1562R (5'CGGCCAGACCGGCTCTAACAC-3') produced a 472 bp amplicon. The PCR products were sequenced by Sanger method at a commercial facility (Macrogen, Seoul, South Korea) and resulted in a combined N-gene sequence of 1492 nucleotides.

Phylogenetic Analysis. The raw sequences were edited with CLC Genomic Workbench Version 3.6.1. Multiple sequence alignment was built with Clustal Omega tool and edited with Jalview package Version 2.8. (Waterhouse et al., 2009) and GeneDoc Version 2.6.002 (Nicholas et al., 1997). Evolutionary analyses were conducted in MEGA6 (Tamura et al., 2013). Entire and partial (positions 56 to 454 according to ERA vaccine strain, GenBank \#EF206707) N-gene sequences of RABVs from Cambodia, Vietnam, China, Thailand, Laos and Myanmar as well as a rabies vaccine strain PV (an outgroup) were included in the study (Supplementary Table 2). To choose the most suitable model for phylogeny, a Model Selection analysis was performed with MEGA6 package (Nei \& Kumar, 2000; Tamura et al., 2013). 
Phylogenetic analyses were conducted on RABV sequences including selected sequences sourced from the GenBank Database. Codon positions included were $1 \mathrm{st}+2 \mathrm{nd}+3 \mathrm{rd}+$ Noncoding. All positions containing gaps and missing data were eliminated. There were a total of 1346 positions in the final dataset for entire $\mathrm{N}$-gene sequences, and 381 positions in the final dataset for partial $\mathrm{N}$-gene sequences. Evolutionary analyses were conducted in MEGA6 (Tamura et al., 2013).

The evolutionary history of the entire N-gene sequences was inferred using the Maximum Likelihood method. The evolutionary distances were computed using the Tamura 3-parameter model (Tamura, 1992). The percentage of trees in which the associated taxa clustered together is shown next to the branches. Initial tree(s) for the heuristic search were obtained by applying the Neighbor-Joining method to a matrix of pairwise distances estimated using the Maximum Composite Likelihood (MCL) approach. A discrete Gamma distribution was used to model evolutionary rate differences among sites $(5$ categories $(+G$, parameter $=0.3114))$. The tree is drawn to scale, with branch lengths measured in the number of substitutions per site. The bootstrap test of phylogeny with 1000 replicates was performed. The analysis involved 192 nucleotide sequences, obtained in the present study (Supplementary Table 1) and retrieved from public databases (Supplementary Table 2).

For the partial N-gene, sequences were analyzed as above with some modifications. The evolutionary history was inferred using the Minimum Evolution (ME) method (Rzhetsky \& Nei, 1992). The tree was drawn to scale, with branch lengths in the same units as those of the evolutionary distances used to infer the phylogenetic tree. The evolutionary distances were computed using the number of differences method (Nei \& Kumar, 2000) and are in the units of the number of base differences per sequence. The ME tree was searched using the Close-Neighbor-Interchange (CNI) algorithm (Nei \& Kumar, 2000) at a search level of 1 . The Neighbor-Joining algorithm (Saitou \& Nei, 1987) was used to generate the initial tree.

2.3. Evolutionary analysis. To determine the comparative evolutionary dynamics of RABVs from Cambodia, we used the BEAST package (Drummond and Rambaut, 2007) to estimate the rate of nucleotide substitution per site, the Time to Most Recent Common Ancestor (TMRCA), and the Maximum Clade Credibility (MCC) tree of the complete coding region of N-gene sequences (Drummond and Rambaut, 2007) utilizing information on the exact year of sample collection. This analysis used the GTR model of nucleotide substitution as well as a different substitution rate for each codon position. A Bayesian Skyline Plot (BSP) was used as a coalescent prior. This provides a piecewise graphical 
depiction of changes of relative genetic diversity through time $\left(\mathrm{N}_{\mathrm{e}} \tau\right)$, where $\mathrm{N}_{\mathrm{e}}$ is the effective population size and $\tau$ is the host-to-host generation time. We also utilized both strict and relaxed (uncorrelated lognormal) molecular clocks. A previous analysis of RABV evolution found that the uncorrelated lognormal relaxed clock and constant population size model provided a better fit to the data (Bourhy et al., 2008), and this was confirmed in a preliminary analysis of our data, although the parameter values estimated were similar under both models. The degree of uncertainty in each parameter estimate is provided by the $95 \%$ highest posterior density (HPD) values, while posterior probability values provide an assessment of the degree of support for each node on the tree. All Markov Chain Monte Carlo chains were run for sufficient time at 200 million steps to ensure statistical convergence, with 10\% removed as burn-in.

\section{Results}

3.1. Sampling. The geographical origins of the Cambodian dog samples analyzed in this study are shown in Figure 1. As there was no information on the exact location where the bite occurred, the cases were attached to the local district health center, which in Cambodia is usually located no more than 5 kilometers from the furthest point of the district.

3.2. Phylogenetic analyses. The complete N-gene sequences of 149 RABV isolates collected in 20 provinces of Cambodia were generated and submitted to GenBank (Supplementary Table 1).

The Model Selection analysis with MEGA6 package revealed that for the dataset of entire and partial nucleoprotein sequences included in the present study, the Tamura 3 - parameter model with a discrete Gamma distribution $(+\mathrm{G})$ had the lowest Bayesian Information Criterion (22395.836 for entire and 10845.81921 for partial nucleoprotein sequences) and was considered to describe the substitution pattern the best.

The complete N-gene sequences (1492 nucleotides in length, positions 71 to 1562, cut with the GeneDoc package to the length of $1346 \mathrm{nt}$ to fit the equal size of the sequences of the reference strains, taken from the public databases) were used to build a Maximum Likelihood tree (Fig. 2).

Phylogenetic reconstruction identified the South-East Asian (SEA) clade that included all the nucleoprotein gene sequences of RABVs from Cambodia, Vietnam, Thailand, Laos and Myanmar. Inside the SEA clade 3 distinct phylogenetic lineages (SEA1, SEA2 and SEA3) were distinguished based on the bootstrap values obtained for the ancestral nodes of each cluster. Most of the viruses from Cambodia 
were closely related to viruses from Thailand, Vietnam and Laos and formed the lineage SEA1. We identified three putative sub-lineages within the SEA1 lineage, and two of them were geographically restricted to Thailand and Laos (putative sub-lineages 2 and 3, respectively). The SEA2 lineage was comprised of two viruses from Cambodia and a group of RABVs from Laos. One of these Cambodian RABVs was isolated from a dog in Phnom Penh in 2005; the second was isolated from a dog in 1997 from Banlung, the capital city of the Ratanakiri province in the North-East part of Cambodia, a region that shares common borders with Laos and Vietnam. This strain was already previously described by Bourhy et al. (2008). The two Cambodian SEA2 strains shared a common ancestor with RABVs isolated in Laos in 1999-2002 (Bourhy et al., 2008) and in 2011-2012 (Ahmed et al., 2015). Viruses from Myanmar formed a separate phylogenetic lineage SEA3.

Phylogenetic analysis was then conducted on 194 partial N-gene sequences generated in the present study and other strains originating from South-East Asian countries (Supplementary Table 2). Rabies virus 9337SWI isolated from a bat in 1993 (EBLV2) was used as an out-group to build this tree. This analysis allowed a comparison with the shorter sequences obtained by Nguyen et al. (2011) from Vietnamese RABVs, resulting in further support for the clade and lineage groupings (Supplementary Fig. 1). The SEA1 lineage, which was initially proposed by Yamagata et al. (2007), was comprised of viruses from Cambodia, Thailand, Laos and Vietnam and corresponded to the subgroup 1a suggested by Nguyen et al. (2011); whereas the SEA2 and SEA3 lineages established in the present study were distinct from the subgroup 1a and 1b, but still contained within the broader Group 1 described previously by Nguyen et al. (2011).

3.3. Evolutionary analysis. Bayesian molecular clock analysis performed on complete N-gene sequences suggested that the TMRCA of all 155 Cambodian rabies viruses dated back to 1950 (95\% HPDs: 1935 to 1961; Fig. 3). The TMRCA of the Cambodian SEA1 lineage was around 1964 (95\% HPDs: 1955 to 1971) and that of SEA2 lineage was around 1953 (95\% HPDs: 1938 to 1969). The nucleotide substitution rate was estimated at $3.13 \times 10^{-4}$ substitutions/site/year (s/s/y; 95\% HPD: $2.46 \times$ $\left.10^{-4}-3.79 \times 10^{-4}\right)$. Using Bayesian skyline plots as an inference tool, the patterns of relative genetic diversity in Cambodian rabies virus increased to its maximum approximately in 2005 followed by a small decline afterward.

\section{Discussion}


Domestic/stray dog rabies is still widespread throughout the world, occurring in over 80 countries/territories (predominantly in the developing world) and is implicated in more than $99 \%$ of all cases of human rabies (WHO, 2012). The present study aimed to provide greater clarity on dog rabies molecular epidemiology in South-East Asian countries using the sequences generated here in addition to the limited number of sequence data publicly available. More specific attention was paid to Cambodia, which is severely affected by rabies but where the epidemiology of the disease remains unclear. Currently, there is no active rabies surveillance system in Cambodia, and the existing data is only available through the rabies diagnosis efforts and the PEP treatment activities of the IPC. As such, reliable analysis of the precise dynamics of dog rabies in Cambodia by year cannot be performed, but the available data confirms that the disease exists and is widespread throughout the country.

Previously a large-scale research study covering South-East Asian countries provided the first definitive evidence for a widely distributed Asian clade comprising viruses from Myanmar, Thailand, Laos, Cambodia, Vietnam and some other countries, but the lineages in which the strains were clustering could not be determined (Bourhy et al., 2008). Ito et al. (1999) performed the first detailed study of rabies molecular epidemiology in Thailand in which six lineages of RABV were identified. At least four of them were endemic to Central (T1C), Southern (T2S) and Northern (T1N1 and T1N2) areas of Thailand whereas the two other lineages (T1CS and T2NC) overlapped different areas. Yamagata et al. (2007) proposed the SEA1 lineage of RABV including viruses from Thailand and Vietnam. Later Nguyen et al. (2011) established the existence of two major RABV lineages in Vietnam (Groups 1 and 2), with Group 1 further subdivided into two subgroups (1A and 1B). Subgroup 1A represented the SEA1 lineage previously described by Yamagata et al. (2007). Subgroup 1B was comprised of viruses from Vietnam, China and Philippines; and Group 2 included viruses from China and Vietnam. Ahmed et al. (2015) summarized that RABVs from Thailand, Malaysia, Cambodia, Laos and Vietnam originated from a common ancestor; and the lineages circulating in Laos were closely related to each other but were not the same as in other South-East Asian countries.

In this first extensive study of RABV molecular epidemiology in Cambodia, a large pool of dog RABV nucleoprotein gene sequences were generated from strains detected in 20 provinces of Cambodia between 1998 and 2011. Figure 1 shows that these viruses were nevertheless mostly collected in the capital and its surrounding provinces. This is because the only rabies diagnostic facility - the Rabies National Reference Centre (IPC, Virology Unit) - and the major post-exposure treatment facility (IPC, Rabies Vaccination Centre) are both located in Phnom Penh. As a result, the samples collected from 
suspected rabid dogs were rarely received from the districts that are very distant from the capital. Nevertheless, IPC's Rabies Reference Centre adequately covers the South-East region of Cambodia, which includes approximately $60-70 \%$ of Cambodian's human and canine populations. Cambodian viruses were included for phylogenetic analysis with RABV sequences from China, Laos, Myanmar, Thailand and Vietnam. Viruses originating from dogs were given preference to be included in analyses. Some human RABV sequences from Vietnam were also included because of the lack of suitable representative sequences from dog origin from this country. However, as dogs are the major rabies reservoir in Asia (Dodet et al., 2001), and most human cases had a history of a dog bite (Nguyen et al., 2011), this should not have introduced a significant bias into the analysis.

The results presented in this study show that the major SEA phylogenetic clade covers at least five countries in the South-East Asian region, including Cambodia, Vietnam, Thailand, Laos and Myanmar. This data, together with the timescale of RABV evolution, are in agreement with the results published earlier by Bourhy et al. (2008). In the present study, we attempted to investigate the presence of distinct phylogenetic lineages inside this large clade.

Most of the lineages identified inside the SEA clade were associated with their geographical origins. All of the viruses from Cambodia, except two (EU086170: Bourhy et al., 2008; and P0709509: this study), clustered with RABVs from Thailand, Vietnam and Laos within the SEA1 lineage, which appears to be the most widespread lineage throughout South-East Asia. We propose the existence of at least 3 putative sub-lineages inside the SEA1 lineage. The sub-lineage 1 comprised RABVs from Cambodia, Thailand, Vietnam and Laos. Two dog RABVs (GQ303556 \& JN786877) clearly formed a distinct sub-lineage 2. Failure of rabies PEP associated with unusual manifestation of the disease was previously described with the strain GQ303556 (Shantavasinkul et al., 2010). The second virus, JN786877, after a series of passages in BHK cells rapidly killed mice inoculated by intramuscular route (Virojanapirom et al., 2012). Although only a small number of viruses from this phylogroup have been described, the potential association of these strains with an increased virulence should be further explored. Sub-lineage 3 comprised RABVs isolated in Laos (2011-2012) described by Ahmed et al. (2015). The SEA1 lineage correlates with the group 1/subgroup 1a, determined earlier by Nguyen et al. (2011) and the South-East Asian lineage 1 identified by Yamagata et al. (2007).

The SEA2 lineage seemed to be distributed in Cambodia and Laos, whereas the distribution of the SEA3 lineage appeared to be limited to Myanmar. The newly established SEA2 lineage comprised several RABVs from Laos and only two Cambodian strains: one from Phnom Penh and one from 
Banlung, located in the North-East of Cambodia near the Laos border. Taking into account that Laos RABVs included in the SEA2 lineage were either from the Vientiane capital, or from the Champasak province which is bordering Cambodia, the circulation of this lineage in Northern Cambodia and Southern Laos with occasional spread to the capitals of the two countries seems plausible. Further studies need to be conducted to confirm the precise origin and distribution of this lineage as there is a clear bias of recruitment of samples towards the capital cities. Only few strains originating from provinces bordering Laos and Vietnam were available for our study: one from the province of Preah Vihear, detected in 2009, and one from Banlung, Ratanakiri province, detected in 2010. It was unfortunately not possible to find any strains from the northern provinces of Cambodia, close to Laos, and thus interpretations must be exercised with caution. In Myanmar, only one lineage of RABVs was identified, comprising the SEA3 group. However, only three RABV sequences from Myanmar were available for analysis, all originating from 1999, so additional studies with more RABV sequences from this country are needed to confirm this observation.

The SEA1 lineage was previously identified by Yamagata et al. (2007) although the bootstrap values were very low (32-40). It comprised viruses from Thailand and Vietnam and the authors proposed that because Cambodia and Laos are situated between Vietnam and Thailand, there was a possibility that RABVs from Cambodia and Laos were genetically related to the SEA1 lineage. This hypothesis is now confirmed by the present study. Such a wide distribution suggests the presence of suitable conditions allowing the intensive circulation of the viruses belonging to that lineage in the dog populations of Thailand, Laos, Cambodia and Vietnam. Illegal trade of stray dogs, essentially for meat consumption, between these four countries could well have contributed to the regional spread of RABVs from the SEA1 lineage (http://www.animals24-7.org/2014/06/08/dog-meat-traffic-still-spreads-rabies-invietnam/; Ahmed et al., 2015).

The evolutionary analysis of the data generated in this study resulted in a comparative evolutionary dynamic analysis of the Cambodian RABVs including the estimation of the rate of nucleotide substitution per site, the TMRCA, and the MCC analysis of the complete coding region of Ngene sequences. Our analysis suggests that the SEA1 lineage had a most recent ancestor in common with the newly established SEA2 lineage. The two lineages apparently diverged around 1950. Interestingly, the SEA2 lineage shared a common ancestor with the Lao viruses around 1953, suggesting that either this lineage was first introduced to Laos from Cambodia and then was largely outcompeted in Cambodia by the SEA1 lineage, or that sporadic introductions of the SEA2 RABVs took place from Laos to 
Cambodia during the 1960s. It is possible that this lineage is more widespread in Cambodia than it appears, but additional studies are required to confirm this hypothesis. During the conflict period of the Khmer Rouge regime, stray dogs almost disappeared due to starvation and human consumption, which could also have impacted the circulation of the RABV lineages in the country. Based on the limited number of sequences available for this analysis, we established that viruses from Myanmar diverged from the other viruses of the major SEA clade approximately in 1942. Interestingly, the viruses of Chinese origin included in this study had a TMRCA around 1734 and since then seem to have evolved independently from the SEA clade.

The present study identified three phylogenetically distinct lineages inside the major South-East Asian phylogenetic clade, with distributions representatives from the five countries in the region. Because the SEA1 lineage was the most widespread in Cambodia, the detection of a new SEA2 lineage in the country could have resulted either from a recent introduction of RABVs from abroad (e.g. Laos), or from the identification of a group of less prevalent viruses. Further molecular and epidemiological investigations are required to answer this question. To elucidate the distribution of the local lineages of the SEA clade and their roles in the molecular epidemiology of rabies, namely the dynamics and spread of rabies in South-East Asia, further studies need to be conducted on an international level. To better define the molecular characteristics of the SEA clade and achieve a more unified terminology, more Asian RABV sequences should be generated, eventually through a regional initiative. These analyses should also include rabies viruses from wildlife and bat Lyssaviruses of South-East Asian origin, the existence of which was suggested based on serological evidence (Reynes et al., 2004).

The wide distribution of the SEA1 lineage across SE Asia suggests a relatively frequent mixing of dog populations throughout the region. This may provide new insights to assist the human and animal health authorities in these countries to take suitable actions to reduce dog circulation in their efforts to eradicate rabies. The Asian Rabies Elimination Strategy (ASEAN, 2015) has outlined the ambitious target of eliminating canine rabies in South-East Asia by 2020. Further clarity on the circulation of RABVs and dog populations will be important information to inform dog population management strategies. 


\section{Acknowledgments}

The authors would like to thank staff of the IPC Rabies Centre and International Centre for Vaccinations and the staff of the IPC Virology Unit.

\section{6. $\quad$ References}

1. Ahmed K, Phommachanh P, Vorachith P, Matsumoto T, Lamaningao P, Mori D, Takaki M, Douangngeun B, Khambounheuang B, Nishizono A. Molecular epidemiology of rabies viruses circulating in two rabies endemic provinces of Laos, 2011-2012: regional diversity in Southeast Asia. PLoS Negl Trop Dis. 2015 Mar 31;9(3):e0003645.

2. ASEAN Rabies Elimination Strategy. Accessed on 3rd November 2015. http://vncdc.gov.vn/files/article attachment/2015/3/endorsed-ares-final.pdf).

3. Bourhy, H., Reynes, J.M., Dunham, E.J., Dacheux, L., Larrous, F., Huong, V.T., Xu, G., Yan, J., Miranda, M.E., Holmes, E.C., 2008. The origin and phylogeography of dog rabies virus. J. Gen. Virol. 89 (PT 11), 2673-2681.

4. Chupin, S.A., Chernysheva, E.V., Metlin, A.E., 2013. Genetic characterization of the rabies virus field isolates detected in Russian Federation within the period 2008-2011. Vopr. Virusol. 58 (4), 44-49.

5. Dacheux, L., Reynes, J.M, Buchy, P., Sivuth, O., Diop, B.M., Rousset, D., Rathat,C., Jolly, N., Dufourcq, J.B.,Nareth C., Diop S., Iehlé C., Rajerison R., Sadorge C., Bourhy H., 2008. A reliable diagnosis of human rabies based on analysis of skin biopsy specimens. Clin. Infect. Dis. 47 (11), 1410-1417.

6. Dean, D.J., Abelseth, M.K., Atanasiu, P.,1996. The fluorescent antibody test. In Laboratory Techniques in Rabies, pp. 88-93. Edited byMeslin F.-X., M.M. Kaplan, H. Koprowski, WHO, Geneva.

7. Dodet, B., Meslin, F.-X., Aubert M., 2001. Executive summary In: Proceedings of 4th International Symposium on Rabies Control in Asia pp. 191-201. Edited by B. Dodet, F-X. Meslin, E. Heseltine.

8. Drummond, A.J., Rambaut, A., 2007. BEAST: Bayesian evolutionary analysis by sampling trees. BMC Evol. Biol. 8, 207-214. 
9. Felsenstein J., 1985. Confidence limits on phylogenies: An approach using the bootstrap. Evolution 39,783-791.

10. Gongal, G., Wright, E., 2011. Human rabies in the WHO Southeast Asian Region: Forward Steps for Elimination Advances in Preventive Medicine. Adv. Prev. Med. 383870.

11. Hampson, K., Coudeville, L., Lembo, T., Sambo, M., Kieffer, A., Attlan, M., Barrat, J., Blanton, J.D., Briggs, D.J., Cleaveland, S., Costa, P., Freuling. C.M., Hiby, E., Knopf, L., Leanes, F., Meslin, F.X., Metlin, A., Miranda, ME., Müller, T., Nel, L.H., Recuenco, S., Rupprecht, C.E., Schumacher, C., Taylor, L., Vigilato, M.A., Zinsstag, J., Dushoff, J.; Global Alliance for Rabies Control Partners for Rabies Prevention., 2015. Estimating the global burden of endemic canine rabies. PLoS Negl. Trop. Dis. 9 (4), e0003709.

12. Holmes, E.C., Woelk, C.H., Kassis, R., Bourhy, H., 2002. Genetic constraints and the adaptive evolution of rabies virus in nature. Virology 292 (2), 247-257.

13. Ito, N., Sugiyama, M., Oraveerakul, K., Piyaviriyakul, P., Lumlertdacha, B., Arai, Y. T., Tamura, Y., Mori, Y., Minamoto, N., 1999. Molecular epidemiology of rabies in Thailand. Microbiol. Immunol. 43 (6), 551-559.

14. Johnson, N., McElhinney, M., Smith, J., Lowings, P., Fooks A.R., 2002. Phylogenetic comparison of the genus Lyssavirus using distal coding sequences of glycoprotein and nucleoprotein genes. Arch. Virol. 147, 2111-2123.

15. Kissi, B., Tordo, N., Bourhy, H., 1995. Genetic polymorphism in the rabies virus nucleoprotein gene. Virology 209 (2), 526-537.

16. Lunney, M., Fèvre, S.J., Stiles, E., Ly, S., San, S., Vong, S.,2012. Knowledge, attitudes and practices of rabies prevention and dog bite injuries in urban and peri-urban provinces in Cambodia, 2009. Int. Health 4(1), 4-9.

17. Ly, S., Buchy, P., Heng, N.Y., Ong, S., Chhor, N., Bourhy, H., Vong S., 2009. Rabies situation in Cambodia. PLoS Negl. Trop. Dis. 3(9).

18. Nei, M., Kumar, S., 2000. Molecular Evolution and Phylogenetics. Oxford University Press, New York.

19. Nicholas, K.B., Nicholas H.B. Jr., Deerfield, D.W. II., 1997. GeneDoc: Analysis and Visualization of Genetic Variation. Emb News 4, 14. 
20. Nguyen, A.K., Nguyen, D.V., Ngo, G.C., Nguyen, T.T., Inoue, S., Yamada, A., Dinh, X.K., Nguyen, D.V., Phan, T.X., Pham, B.Q., Nguyen, H.T., Nguyen, H.T., 2011. Molecular epidemiology of rabies virus in Vietnam (2006-2009). Jpn. J. Infect. Dis. 64 (5), 391-396.

21. Reynes, J. M., Soares, J. L., Keo, C., Ong, S., Heng, N.Y., Vanhoye, B., 1999. Characterization and observation of animals responsible for rabies post-exposure treatment in Phnom Penh, Cambodia. Onderstepoort J. Vet. Res. 66(2), 129-133.

22. Reynes, J. M., Molia S., Audry, L., Hout, S., Ngin, S., Walson, J., Bourhy H., 2004. Serologic evidence of Lyssavirus infection in bats, Cambodia. Emerg. Infect. Dis. 10 (12), 2231-2234.

23. Rzhetsky, A., Nei, M., 1992. A simple method for estimating and testing minimum evolution trees. Mol. Biol. Evol. 9:945-967.

24. Saitou, N., Nei, M., 1987. The neighbor-joining method: A new method for reconstructing phylogenetic trees. Molecular Biology and Evolution 4, 406-425.

25. Shantavasinkul, P., Tantawichien, T., Wacharapluesadee, S., Jeamanukoolkit, A., Udomchaisakul, P., Chattranukulchai, P., Wongsaroj, P., Khawplod, P., Wilde, H., Hemachudha, T., 2010. Failure of rabies postexposure prophylaxis in patients presenting with unusual manifestations. Clin. Infect. Dis. 50 (1), 77-79.

26. Tamura K., 1992. Estimation of the number of nucleotide substitutions when there are strong transition-transversion and G + C-content biases. Mol. Biol. Evol. 9, 678-687.

27. Tamura, K., Stecher, G., Peterson, D., Filipski, A., Kumar, S., 2013. MEGA6: Molecular Evolutionary Genetics Analysis version 6.0. Mol. Biol. Evol. 30, 2725-2729.

28. Tordo, N., Poch, O., Ermine, A., Keith, G.,Rougeon, F., 1986. Walking along the rabies genome: is the large G-L intergenic region a remnant gene? Proc. Natl. Acad. Sci. U.S.A. 83 (11), 3914-3918.

29. Tordo, N., Kouknetzoff, A., 1993. The rabies virus genome: an overview. Onderstepoort J. Vet. Res. 60, 263-269.

30. Virojanapirom, P., Khawplod, P., Sawangvaree, A., Wacharapluesadee, S., Hemachudha, T., Yamada,K., Morimoto, K., Nishizono, A., 2012. Molecular analysis of the mutational effects of Thai street rabies virus with increased virulence in mice after passages in the BHK cell line. Arch. Virol. 157 (11), 2201-2205. 
31. Waterhouse, A.M., Procter, J.B., Martin, D.M.A., Clamp, M., Barton, G. J., 2009. Jalview Version 2 - a multiple sequence alignment editor and analysis workbench. Bioinformatics 25, 1189-1191.

32. WHO Expert Consultation on Rabies, 2012. Second report. Geneva, World Health Organization, WHO Technical Report Series, No. 982.

33. Yamagata J., Ahmed K., Khavplod P., Mannen K., Xuyen D.K., Loi H.H., Dung N.V., Nishizono A., 2007. Molecular epidemiology of rabies in Vietnam. Microbiol. Immunol. 51 (9), 833-840.

34. Yang, D.K., Park, Y.N., Hong, G.S., Kang, H.K., Oh, Y.I., Cho, S.D., Song, J.Y.,2011. Molecular characterization of Korean rabies virus isolates. J. Vet. Sci. 12 (1): 57-63 
Figure 1. Geographical origins of the Cambodian rabies viruses sequenced for the purpose of the present study. The map was built with ArcMap 10 package (ESRI, Redlands, CA, USA).

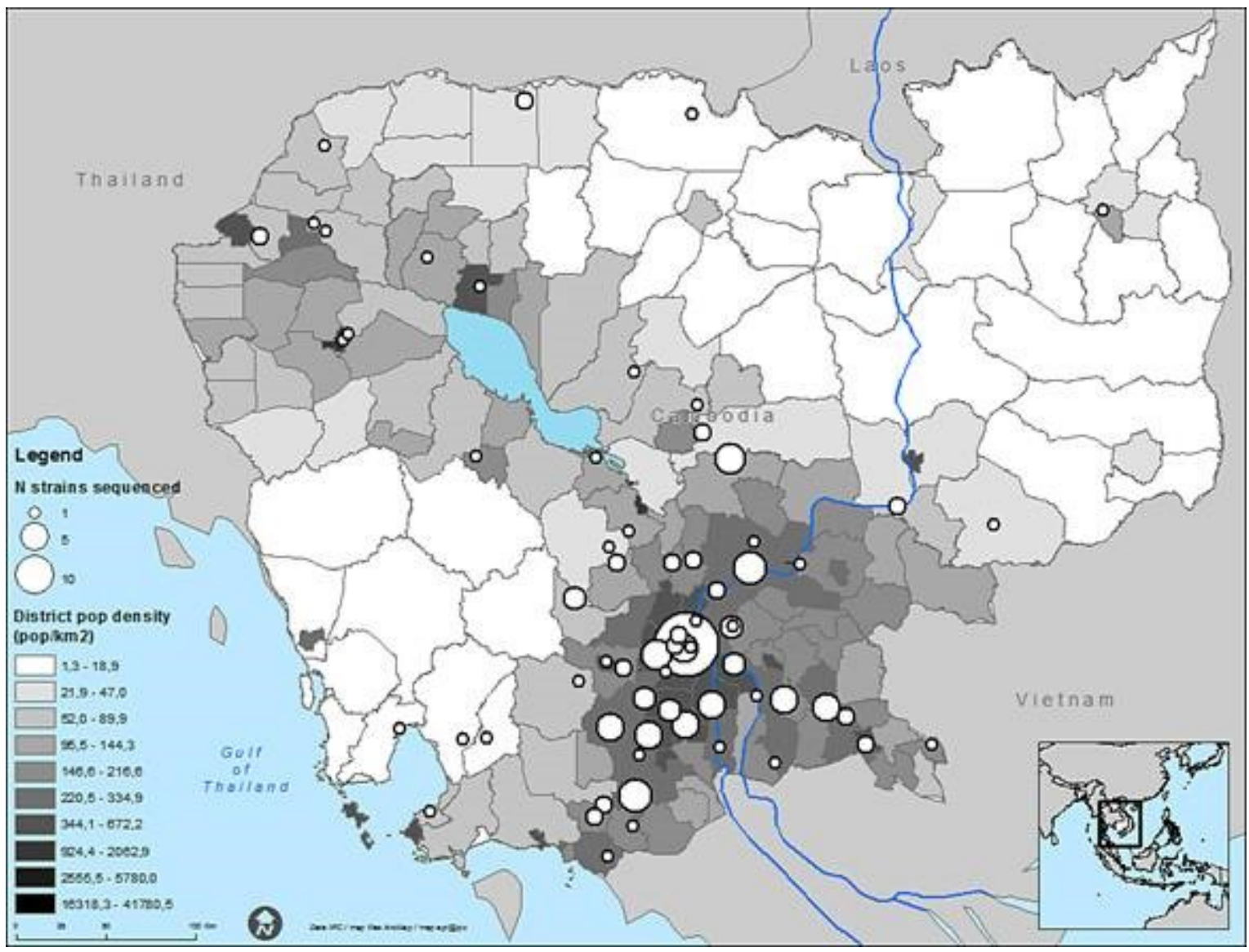


Figure 2. Evolutionary relationships of South-East Asian rabies viruses based on complete N-gene sequences. The tree was built using Maximum Likelihood method based on Tamura 3-parameter method (Tamura, 1992) to compute the evolutionary distances. The tree with the highest log likelihood $(-7633.4158)$ is shown. The percentage of trees in which the associated taxa clustered together is shown next to the branches. The tree is drawn to scale, with branch lengths measured in the number of substitutions per site. The analysis involved 192 nucleotide sequences. There were a total of 1346 positions in the final dataset. Bootstrap values lower than 70 are hidden.

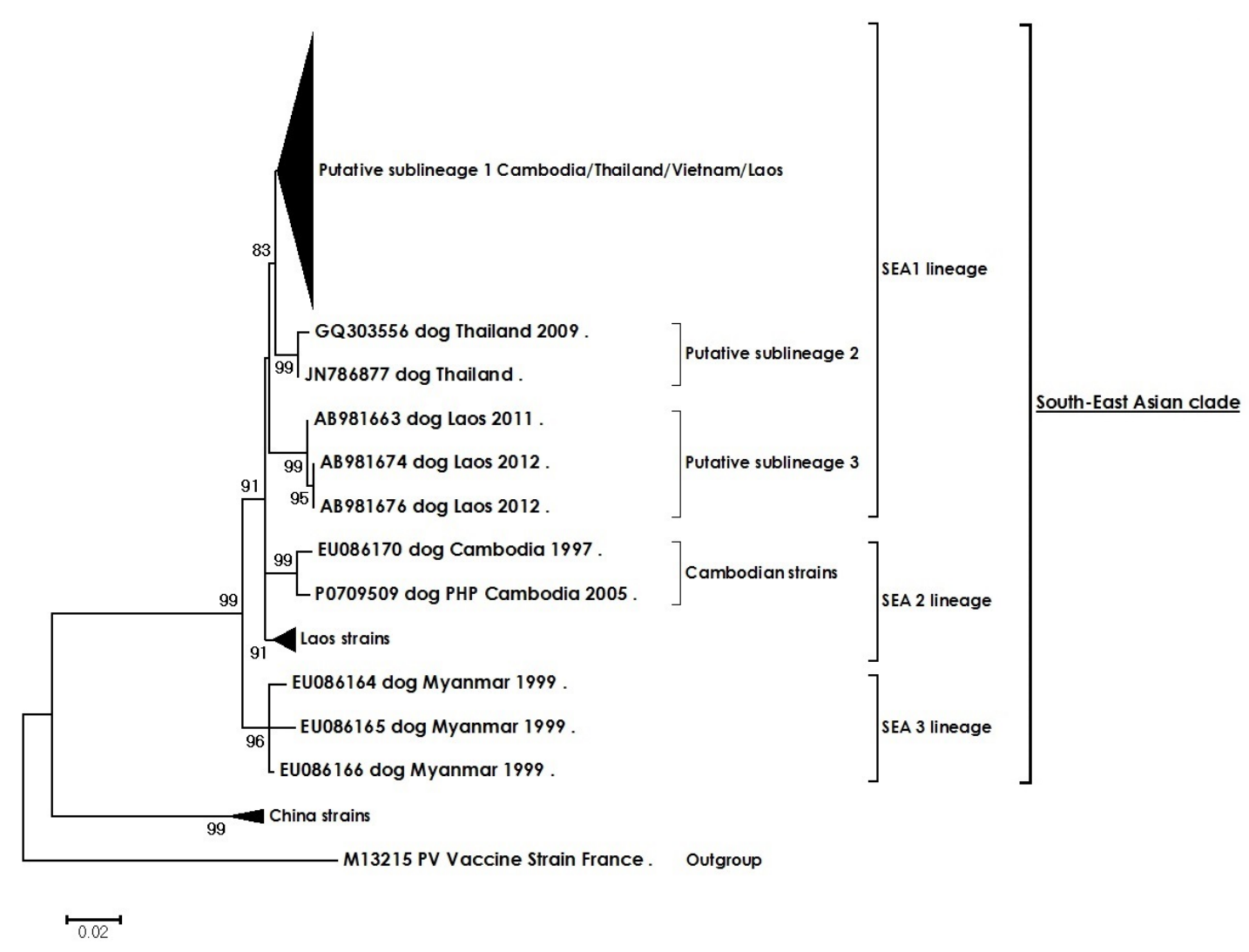


Figure 3. A. Maximum clade credibility tree of 190 complete coding region of nucleoprotein gene sequences of rabies viruses. The estimated TMRCA are indicated next to each node. Branches are color-coded by country of origin: dark blue for Cambodia, pink for Vietnam, red for Thailand, green for Laos, sky-blue for Myanmar and purple for China. The horizontal axis is shown as the number of years from the most recent sample. B. Population dynamics of rabies viruses (complete coding region of nucleoprotein gene sequences). The Bayesian skyline plot shows changes in relative genetic diversity ( $\mathrm{X}$ axis) and time ( $\mathrm{Y}$ axis) is shown as the number of years from the most recent sample. The black solid line represents the mean estimate of $\mathrm{Ne} \tau$, while the 95\% HPD intervals are shown in grey solid line. RABV sequence JN786877was excluded from this analysis (absence of information regarding the date of isolation).

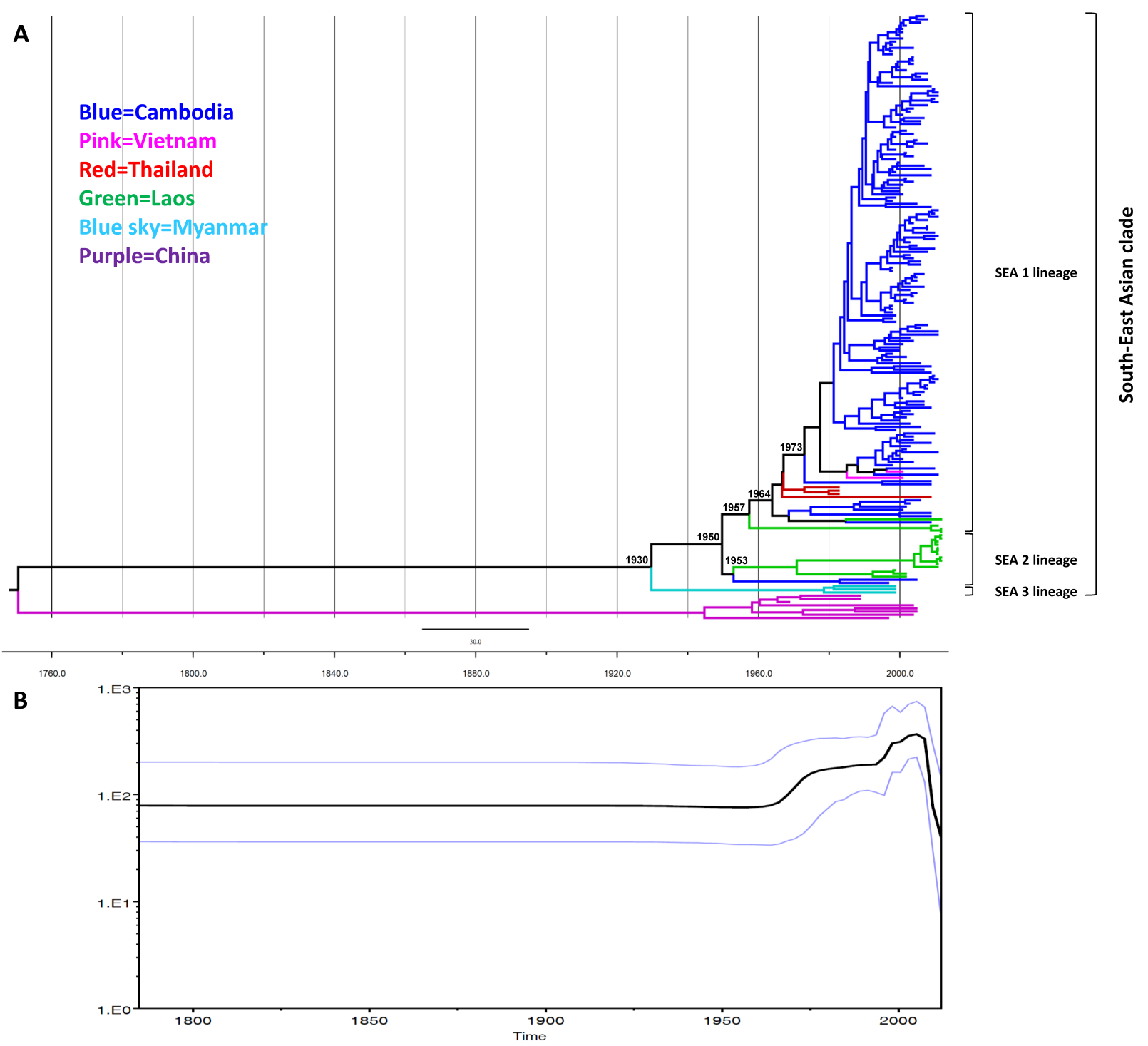


Table 1. PCR and sequencing primers used in this study

\begin{tabular}{|c|c|c|c|}
\hline No & $\begin{array}{l}\text { Name of } \\
\text { PCR primers }\end{array}$ & Sequence 5' - 3' & References \\
\hline \multicolumn{4}{|c|}{ PCR primers } \\
\hline 1 & PV 05m & ATG ACA GAC AAY YTG AAC AA & \multirow{5}{*}{ Dacheux L. et al., 2008} \\
\hline 2 & PV 09 & TGA CCA TTC CAR CAR GTN G & \\
\hline 3 & PV 08 & GGT CTG ATC TRT CWG ARY AAT A & \\
\hline 4 & $\beta-$ Taq1 & TCACCCACACTGTGCCCATCTACGA & \\
\hline 5 & $\beta-$ Taq2 & CAGCGGAACCGCTCATTGCCAATGG & \\
\hline \multicolumn{4}{|c|}{$\begin{array}{l}\text { Sequencing primers } \\
\end{array}$} \\
\hline 1. & RVN-71F & ATGGATGCCGACAAGATTGTATTC & \multirow{4}{*}{ Yang et al., 2011} \\
\hline 2. & RVN-1118R & GAATTCCTCTCCCAGATAGCC & \\
\hline 3. & RVN-1091F & CTAGGGGGCTATCTGGGAGA & \\
\hline 4. & RVN-1562R & CGGCCAGACCGGCTCTAACAC & \\
\hline
\end{tabular}


APPENDIX

\section{Supplementary Table 1.}

Information on dog rabies samples from Cambodia

\begin{tabular}{|c|c|c|c|c|c|c|}
\hline № & Animal ID & Year & Age (month) & Date of sampling & Province* & $\begin{array}{c}\text { GenBank } \\
\text { accession number }\end{array}$ \\
\hline 1 & I0119310 & 1998 & 6 & 19-01-98 & PHP & KM366330 \\
\hline 2 & I0209267 & 1998 & 12 & $07-02-98$ & $\mathrm{KCHA}$ & KM366285 \\
\hline 3 & I0515204 & 1998 & 30 & $15-05-98$ & KAN & KM366251 \\
\hline 4 & I0715237 & 1998 & 24 & $15-07-98$ & KAN & KM366307 \\
\hline 5 & I0828199 & 1998 & 12 & $28-08-98$ & KAN & KM366329 \\
\hline 6 & I0918204 & 1998 & 12 & $18-09-98$ & PHP & KM366252 \\
\hline 7 & I1020180 & 1998 & 12 & $20-10-98$ & KAN & KM366332 \\
\hline 8 & I1026327 & 1998 & 36 & $26-10-98$ & KSP & KM366306 \\
\hline 9 & $\mathrm{I} 1203073$ & 1998 & 120 & $03-12-98$ & $\mathrm{KCHN}$ & KM366213 \\
\hline 10 & I1209219 & 1998 & 12 & $09-12-98$ & $\mathrm{KCHA}$ & KM366287 \\
\hline 11 & $\mathrm{~J} 0104103$ & 1999 & 18 & 04-01-99 & KAN & KM366234 \\
\hline 12 & $\mathrm{~J} 0122226$ & 1999 & 18 & $22-01-99$ & KMP & KM366269 \\
\hline 13 & J0126058 & 1999 & 12 & 25-01-99 & KCHA & KM366309 \\
\hline 14 & J0127108 & 1999 & 36 & $27-01-99$ & PVG & KM366241 \\
\hline 15 & J0129141 & 1999 & 10 & $29-01-99$ & PHP & KM366328 \\
\hline 16 & J0609146 & 1999 & 24 & 09-06-99 & TAK & KM366327 \\
\hline 17 & $\mathrm{~J} 0701083$ & 1999 & 18 & 01-07-99 & PHP & KM366239 \\
\hline 18 & $\mathrm{~J} 0708136$ & 1999 & 24 & 08-07-99 & KSP & KM366295 \\
\hline 19 & J0806177 & 1999 & 60 & 06-08-99 & KMP & KM366334 \\
\hline 20 & K0208220 & 2000 & 4 & 08-02-00 & TAK & KM366224 \\
\hline 21 & K0329084 & 2000 & 18 & 29-03-00 & $\mathrm{KCHA}$ & KM366326 \\
\hline 22 & K0424232 & 2000 & 24 & 24-04-00 & KSP & KM366245 \\
\hline 23 & K0608309 & 2000 & 7 & 08-06-00 & KSP & KM366210 \\
\hline 24 & K0609224 & 2000 & 7 & 09-06-00 & PVG & KM366275 \\
\hline 25 & K0802312 & 2000 & 7 & $02-08-00$ & PHP & KM366265 \\
\hline 26 & K0816099 & 2000 & 24 & $16-08-00$ & KAN & KM366335 \\
\hline 27 & K0830060 & 2000 & 24 & $30-08-00$ & $\mathrm{KCHA}$ & KM366282 \\
\hline 28 & K1222058 & 2000 & 5 & $22-12-00$ & TAK & KM366224 \\
\hline 29 & L0116088 & 2001 & 3 & 16-01-01 & KMP & KM366325 \\
\hline 30 & L0324078 & 2001 & 5 & 24-03-01 & PHP & KM366226 \\
\hline 31 & L0411161 & 2001 & 36 & $11-04-01$ & PVG & KM366264 \\
\hline 32 & L0524176 & 2001 & 7 & $24-05-01$ & KSP & KM366278 \\
\hline 33 & L0705247 & 2001 & 3 & 05-07-01 & KAN & KM366304 \\
\hline 34 & L0920218 & 2001 & 24 & 20-09-01 & KTH & KM366242 \\
\hline 35 & L0925517 & 2001 & 24 & $25-09-01$ & $\mathrm{OMC}$ & KM366271 \\
\hline 36 & L1025187 & 2001 & 48 & $25-10-01$ & TAK & KM366321 \\
\hline 37 & L1213232 & 2001 & 24 & $13-12-01$ & $\mathrm{KCHN}$ & KM366240 \\
\hline 38 & L1226153 & 2001 & 5 & $26-12-01$ & KCHA & KM366290 \\
\hline 39 & M0218288 & 2002 & 36 & $18-02-02$ & KRA & KM366256 \\
\hline 40 & M0316063 & 2002 & 72 & $16-03-02$ & BMC & KM366298 \\
\hline
\end{tabular}




\begin{tabular}{|c|c|c|c|c|c|c|}
\hline 41 & M0506147 & 2002 & 36 & 06-05-02 & KMP & KM366260 \\
\hline 42 & M0516129 & 2002 & 6 & $16-05-02$ & OMC & KM366209 \\
\hline 43 & M0805218 & 2002 & 12 & 05-08-02 & PVG & KM366305 \\
\hline 44 & M0830377 & 2002 & 36 & $30-08-02$ & KAN & KM366233 \\
\hline 45 & M0906103 & 2002 & 24 & 06-09-02 & KSP & KM366300 \\
\hline 46 & M1002140 & 2002 & 18 & $02-10-02$ & TAK & KM366215 \\
\hline 47 & M1102092 & 2002 & 12 & 04-11-02 & $\mathrm{KTH}$ & KM366247 \\
\hline 48 & M1213229 & 2002 & 96 & $13-12-02$ & PHP & KM366227 \\
\hline 49 & N0120098 & 2003 & 24 & $20-01-03$ & TAK & KM366317 \\
\hline 50 & N0212228 & 2003 & 12 & $12-02-03$ & $\mathrm{KCHA}$ & KM366232 \\
\hline 51 & N0728149 & 2003 & 48 & $28-07-03$ & KSP & KM366218 \\
\hline 52 & N0516416 & 2003 & 12 & $16-05-03$ & PVG & KM366308 \\
\hline 53 & N0616208 & 2003 & 36 & $16-06-03$ & KAN & KM366250 \\
\hline 54 & N0711309 & 2003 & 12 & $11-07-03$ & PHP & KM366214 \\
\hline 55 & N0915299 & 2003 & 24 & $15-09-03$ & $\mathrm{KTH}$ & KM366324 \\
\hline 56 & N1011101 & 2003 & 24 & $11-10-03$ & KMP & KM366270 \\
\hline 57 & N1222113 & 2003 & 12 & $22-12-03$ & $\mathrm{BMC}$ & KM366291 \\
\hline 58 & N1229390 & 2003 & 3 & $29-12-03$ & $\mathrm{KCHN}$ & KM366272 \\
\hline 59 & O0109375 & 2004 & 24 & 09-01-04 & SRP & KM366204 \\
\hline 60 & O0128528 & 2004 & 24 & 28-01-04 & SVR & KM366302 \\
\hline 61 & O0403503 & 2004 & 36 & 02-04-04 & PHP & KM366339 \\
\hline 62 & O0422539 & 2004 & 2 & 22-04-04 & PHP & KM366340 \\
\hline 63 & O0527523 & 2004 & 36 & $27-05-04$ & PHP & KM366341 \\
\hline 64 & O0727536 & 2004 & 48 & $27-07-04$ & PHP & KM366342 \\
\hline 65 & O0906554 & 2004 & 36 & 06-09-04 & PHP & KM366343 \\
\hline 66 & O1104507 & 2004 & 36 & 04-11-04 & PHP & KM366344 \\
\hline 67 & O1106516 & 2004 & 5 & 06-11-04 & PHP & KM366345 \\
\hline 68 & O1216508 & 2004 & 36 & $16-12-04$ & PHP & KM366349 \\
\hline 69 & O0730514 & 2004 & 24 & $30-07-04$ & PHP & KM366350 \\
\hline 70 & O0217545 & 2004 & 12 & $17-02-04$ & $\mathrm{KCHA}$ & KM366313 \\
\hline 71 & O0405536 & 2004 & 24 & 05-04-04 & KCHN & KM366206 \\
\hline 72 & O0518537 & 2004 & 9 & $18-05-04$ & PVG & KM366208 \\
\hline 73 & O0625524 & 2004 & 5 & $25-06-04$ & KAN & KM366297 \\
\hline 74 & O0716535 & 2004 & 5 & $16-07-04$ & KSP & KM366219 \\
\hline 75 & O0831550 & 2004 & 12 & $31-08-04$ & KMP & KM366273 \\
\hline 76 & O1025556 & 2004 & 2 & $25-10-04$ & PHP & KM366259 \\
\hline 77 & P0324529 & 2005 & 7 & 24-03-05 & PHP & KM366346 \\
\hline 78 & P0622512 & 2005 & 12 & 22-06-05 & PHP & KM366347 \\
\hline 79 & P0407547 & 2005 & 3 & 07-04-05 & SRP & KM366249 \\
\hline 80 & P0416516 & 2005 & 3 & 16-04-05 & $\mathrm{KCHN}$ & KM366316 \\
\hline 81 & P0709509 & 2005 & 2 & 09-07-05 & PHP & KM366268 \\
\hline 82 & P1110521 & 2005 & 96 & $10-11-05$ & KRA & KM366261 \\
\hline 83 & P1114533 & 2005 & 4 & $14-11-05$ & KTH & KM366312 \\
\hline 84 & Q0105521 & 2006 & 24 & 05-01-06 & KTH & KM366292 \\
\hline 85 & Q1023563 & 2006 & 9 & $23-10-06$ & PHP & KM366348 \\
\hline 86 & Q0201551 & 2006 & 3 & $01-02-06$ & BBG & KM366203 \\
\hline 87 & Q0320591 & 2006 & 5 & 20-03-06 & $\mathrm{KCHA}$ & KM366258 \\
\hline 88 & Q0420515 & 2006 & 36 & $20-04-06$ & TAK & KM366315 \\
\hline 89 & Q0428502 & 2006 & 12 & $27-04-06$ & KAN & KM366248 \\
\hline
\end{tabular}




\begin{tabular}{|c|c|c|c|c|c|c|}
\hline 90 & Q0810538 & 2006 & 36 & $10-08-06$ & PVG & KM366257 \\
\hline 91 & Q0914536 & 2006 & 12 & $14-09-06$ & KMP & KM366276 \\
\hline 92 & Q1028515 & 2006 & 3 & $28-10-06$ & KSP & KM366323 \\
\hline 93 & Q1129522 & 2006 & 3 & 29-11-06 & KKG & KM366246 \\
\hline 94 & Q1225533 & 2006 & 24 & $25-12-06$ & PHP & KM366294 \\
\hline 95 & R0110558 & 2007 & 60 & $10-01-07$ & KSP & KM366296 \\
\hline 96 & R0222564 & 2007 & 24 & $22-02-07$ & BMC & KM366293 \\
\hline 97 & R0326539 & 2007 & 12 & 26-03-07 & TAK & KM366243 \\
\hline 98 & R0418567 & 2007 & 2 & 18-04-07 & KMP & KM366311 \\
\hline 99 & R0528536 & 2007 & 5 & $28-05-07$ & PVG & KM366253 \\
\hline 100 & R0802504 & 2007 & 12 & 02-08-07 & PHP & KM366289 \\
\hline 101 & R0919544 & 2007 & 36 & 19-09-07 & KAN & KM366207 \\
\hline 102 & R1105511 & 2007 & 24 & 05-11-07 & $\mathrm{KTH}$ & KM366320 \\
\hline 103 & R1211946 & 2007 & 60 & $11-12-07$ & SVR & KM366303 \\
\hline 104 & S0407603 & 2008 & 12 & 07-04-08 & PHP & KM366228 \\
\hline 105 & S0529625 & 2008 & 24 & $29-05-08$ & $\mathrm{KCHN}$ & KM366310 \\
\hline 106 & S0614621 & 2008 & 12 & 14-06-08 & KAN & KM366212 \\
\hline 107 & S0717637 & 2008 & 72 & $17-07-08$ & KAN & KM366236 \\
\hline 108 & S0717641 & 2008 & 24 & $17-07-08$ & KAN & KM366281 \\
\hline 109 & S0804664 & 2008 & 18 & 04-08-08 & PVG & KM366274 \\
\hline 110 & S0821644 & 2008 & 48 & 21-08-08 & KSP & KM366231 \\
\hline 111 & S1014618 & 2008 & 24 & 14-10-08 & SVR & KM366319 \\
\hline 112 & S1030654 & 2008 & 36 & $30-10-08$ & TAK & KM366202 \\
\hline 113 & S1103646 & 2008 & 24 & 03-11-08 & KKG & KM366237 \\
\hline 114 & S1201660 & 2008 & 84 & $01-12-08$ & PUR & KM366280 \\
\hline 115 & S1222692 & 2008 & 24 & $22-12-08$ & TAK & KM366279 \\
\hline 116 & T0126697 & 2009 & 2 & 26-01-09 & PRV & KM366299 \\
\hline 117 & T0216672 & 2009 & 72 & 16-02-09 & $\mathrm{KTH}$ & KM366288 \\
\hline 118 & T0223715 & 2009 & 3 & 23-02-09 & KCHA & KM366238 \\
\hline 119 & T0325655 & 2009 & 36 & 25-03-09 & $\mathrm{KKG}$ & KM366217 \\
\hline 120 & T0509634 & 2009 & 24 & 09-05-09 & KSP & KM366337 \\
\hline 121 & T0602630 & 2009 & 24 & 02-06-09 & TAK & KM366235 \\
\hline 122 & T0617644 & 2009 & 72 & 17-06-09 & $\mathrm{KSO}$ & KM366331 \\
\hline 123 & T0622656 & 2009 & 6 & 22-06-09 & BBG & KM366283 \\
\hline 124 & T0716615 & 2009 & 48 & 16-07-09 & PHP & KM366254 \\
\hline 125 & T0819633 & 2009 & 24 & 19-08-09 & $\mathrm{KCHN}$ & KM366301 \\
\hline 126 & T0905602 & 2009 & 24 & 05-09-09 & $\mathrm{BMC}$ & KM366314 \\
\hline 127 & T1002618 & 2009 & 12 & 02-10-09 & KAN & KM366262 \\
\hline 128 & T1221671 & 2009 & 48 & 21-12-09 & KMP & KM366333 \\
\hline 129 & U0116621 & 2010 & 12 & 16-01-10 & KAN & KM366338 \\
\hline 130 & U0224649 & 2010 & 6 & $24-02-10$ & $\mathrm{KCHA}$ & KM366223 \\
\hline 131 & U0309717 & 2010 & 3 & 09-03-10 & KCHN & KM366211 \\
\hline 132 & U0419635 & 2010 & 24 & 19-04-10 & KMP & KM366336 \\
\hline 133 & U0520629 & 2010 & 12 & $20-05-10$ & KSP & KM366216 \\
\hline 134 & U0628690 & 2010 & 120 & $28-06-10$ & KTH & KM366318 \\
\hline 135 & U0717622 & 2010 & 12 & $17-07-10$ & PVG & KM366205 \\
\hline 136 & U0726692 & 2010 & 36 & 26-07-10 & SVR & KM366227 \\
\hline 137 & U0821622 & 2010 & 24 & $21-08-10$ & PHP & KM366267 \\
\hline 138 & U1230640 & 2010 & 7 & $30-12-10$ & RAT & KM366266 \\
\hline
\end{tabular}




\begin{tabular}{|l|l|l|c|c|c|l|}
\hline 139 & V0208630 & 2011 & 5 & $08-02-11$ & BMC & KM366230 \\
\hline 140 & V0408641 & 2011 & 24 & $08-04-11$ & KAN & KM366322 \\
\hline 141 & V0411671 & 2011 & 36 & $11-04-11$ & KCHA & KM366220 \\
\hline 142 & V0520617 & 2011 & 3 & $20-05-11$ & PHP & KM366229 \\
\hline 143 & V0627625 & 2011 & 36 & $27-06-11$ & KTH & KM366222 \\
\hline 144 & V0726646 & 2011 & 12 & $26-07-11$ & KMP & KM366284 \\
\hline 145 & V0808656 & 2011 & 36 & $08-08-11$ & KRA & KM366221 \\
\hline 146 & V0926624 & 2011 & 24 & $26-09-11$ & KAN & KM366255 \\
\hline 147 & V1018638 & 2011 & 24 & $18-10-11$ & PVG & KM366225 \\
\hline 148 & V1114631 & 2011 & 72 & $14-11-11$ & KSP & KM366286 \\
\hline 149 & V1223621 & 2011 & 12 & $23-12-11$ & TAK & KM366263 \\
\hline
\end{tabular}

*Province codes: BBG - Battambang; BMC - Banteay Meanchey; KAN - Kandal; KCHA - Kampong Cham; KCHN - Kampong Chnang; KKG - Koh Kong; KMP-Kampot; KRA - Kratie; KSO - Kampong Som; KSP - Kampong Speu; KTH - Kampong Thom; OMC -Oudor Meanchey; PHP - Phnom Penh; PRV-Preah Vihear; PUR - Pursat; PVG -Prey Veng; RAT - Ratanakiri; SRP - Siem Reap; SVR - Svay Reang. 


\section{Supplementary Figure 1. Evolutionary relationships of rabies viruses from South-East Asia} based on partial N-gene sequences. The tree was built using Minimum Evolution method (Rzhetsky \& Nei, 1992). The optimal tree with the sum of branch length $=304.71612549$ is shown. The percentage of replicate trees in which the associated taxa clustered together in the bootstrap test (1000 replicates) are shown next to the branches (Felsenstein, 1985). Boot strap values lower 70 are hidden. There were a total of 381 positions in the final dataset.

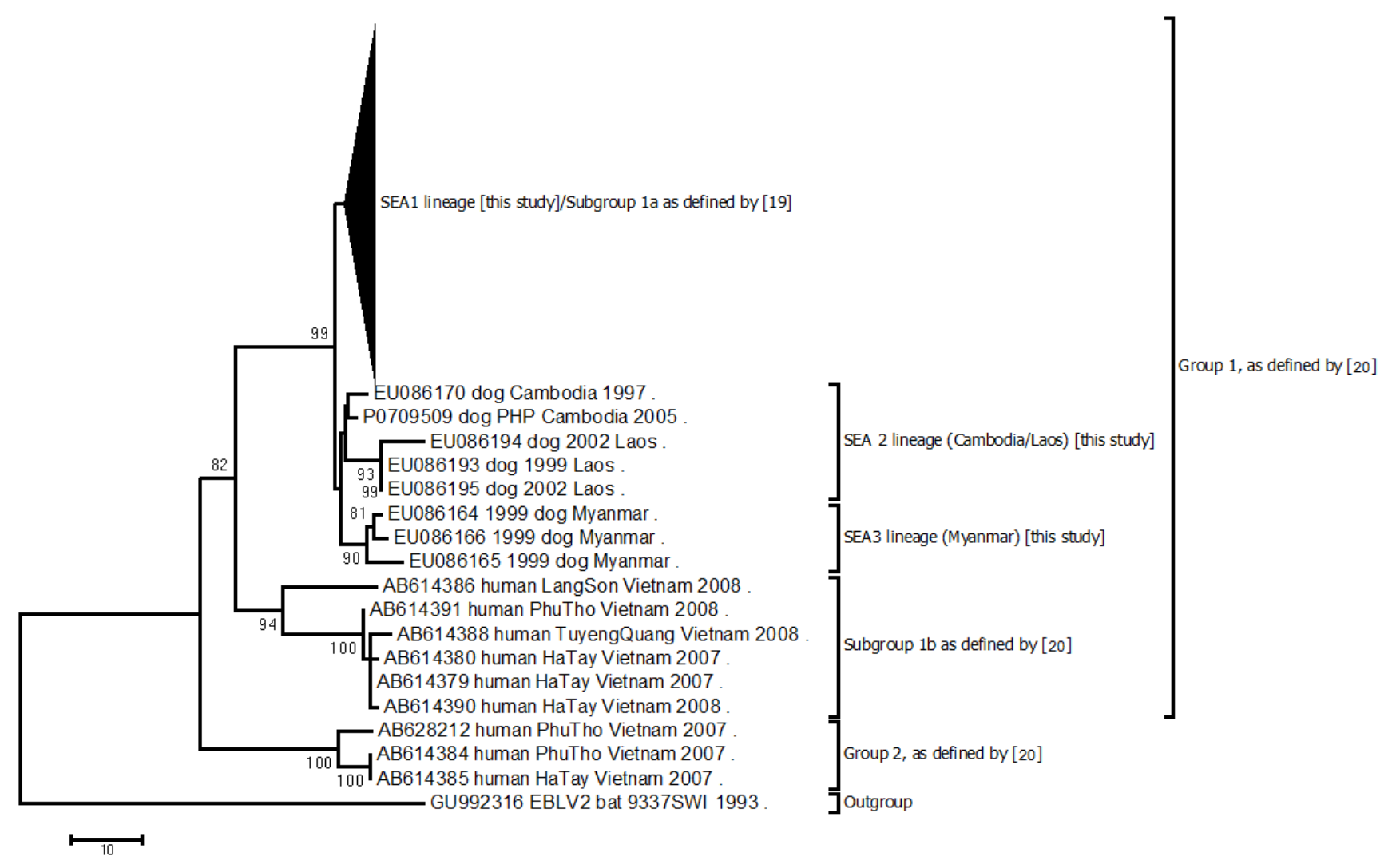




\section{Supplementary Table 2.}

Information on the reference sequences

\begin{tabular}{|c|c|c|c|c|c|c|}
\hline No & Strain Name & Country & Year & Species & $\begin{array}{l}\text { GenBank } \\
\text { accession \# }\end{array}$ & Reference \\
\hline 1. & 9916CBG & \multirow{6}{*}{ Cambodia } & 1999 & \multirow{6}{*}{$\operatorname{dog}$} & EU086171 & \multirow{8}{*}{ Bourhy et. al., 2008} \\
\hline 2. & 02006CBG & & 1998 & & EU086172 & \\
\hline 3. & 9912CBG & & 1998 & & EU086169 & \\
\hline 4. & 9911CBG & & 1998 & & EU086168 & \\
\hline 5. & 9908CBG & & 1998 & & EU086167 & \\
\hline 6. & 9914CBG & & 1997 & & EU086170 & \\
\hline 7. & $01017 \mathrm{VNM}$ & \multirow{16}{*}{ Vietnam } & 2001 & \multirow{5}{*}{$\operatorname{dog}$} & EU086210 & \\
\hline 8. & 01016VNM & & 2001 & & EU086209 & \\
\hline 9. & VN3 & & n.a.* & & AB116579 & \multirow{2}{*}{$\begin{array}{l}\text { Minoura and Nishizono } \\
\text { direct submission }\end{array}$} \\
\hline 10. & VN52 & & n.a. & & AB116580 & \\
\hline 11. & D 150 & & 2006 & & AB614373 & \multirow{9}{*}{ Nguyen et al., 2011} \\
\hline 12. & H130108 & & 2008 & \multirow{8}{*}{ human } & AB614386 & \\
\hline 13. & H210608 & & 2008 & & AB614391 & \\
\hline 14. & H200608 & & 2008 & & AB614390 & \\
\hline 15. & H010607 & & 2007 & & AB614379 & \\
\hline 16. & H150308 & & 2008 & & AB614388 & \\
\hline 17. & H060907 & & 2007 & & AB628212 & \\
\hline 18. & H111007 & & 2007 & & AB614385 & \\
\hline 19. & H091007 & & 2007 & & AB614384 & \\
\hline 20. & HCM2 & & n.a. & \multirow{3}{*}{$\operatorname{dog}$} & AB299033 & \multirow{3}{*}{$\begin{array}{l}\text { Nishizono Direct } \\
\text { Submission }\end{array}$} \\
\hline 21. & HCM1 & & n.a. & & AB299032 & \\
\hline 22. & HCM7 & & n.a. & & AB299036 & \\
\hline 23. & 8764THA & \multirow{6}{*}{ Thailand } & 1983 & $\operatorname{dog}$ & GU992307 & $\begin{array}{l}\text { Vandekerkhove,J. et al., } \\
\text { unpublished }\end{array}$ \\
\hline 24. & UA341 & & 2009 & human & GQ303555 & \multirow{2}{*}{$\begin{array}{l}\text { Shantavasinkul,P., et al., } \\
2010\end{array}$} \\
\hline 25. & D9/52 & & 2009 & \multirow{4}{*}{$\operatorname{dog}$} & GQ303556 & \\
\hline 26. & QS-05 & & n.a. & & JN786877 & Virojanapirom et al., 2012 \\
\hline 27. & 8743THA & & 1983 & & EU086207 & \multirow{16}{*}{ Bourhy et. al., 2008} \\
\hline 28. & 8734THA & & 1983 & & EU086206 & \\
\hline 29. & 9915BIR & \multirow{3}{*}{ Myanmar } & 1999 & \multirow{3}{*}{$\operatorname{dog}$} & EU086166 & \\
\hline 30. & 9909BIR & & 1999 & & EU086164 & \\
\hline 31. & 9913BIR & & 1999 & & EU086165 & \\
\hline 32. & "05008CHI & \multirow{8}{*}{ China } & 2004 & \multirow{8}{*}{$\operatorname{dog}$} & EU086189 & \\
\hline 33. & 05009CHI & & 2005 & & EU086190 & \\
\hline 34. & 02045CHI & & 1989 & & EU086181 & \\
\hline 35. & 02044CHI & & 1989 & & EU086180 & \\
\hline 36. & $02042 \mathrm{CHI}$ & & 1969 & & EU086178 & \\
\hline 37. & $05007 \mathrm{CHI}$ & & 2004 & & EU086188 & \\
\hline 38. & $05005 \mathrm{CHI}$ & & 2005 & & EU086186 & \\
\hline 39. & $02037 \mathrm{CHI}$ & & 1997 & & EU086175 & \\
\hline 40. & "02002LAO & \multirow{6}{*}{ Laos } & 2002 & \multirow{6}{*}{$\operatorname{dog}$} & EU086195 & \\
\hline 41. & 9910LAO & & 1999 & & EU086193 & \\
\hline 42. & 02001LAO & & 2002 & & EU086194 & \\
\hline 43. & Lao1 & & 2011 & & AB981665 & \multirow{3}{*}{ Ahmed et al., 2015} \\
\hline 44. & Lao2 & & 2011 & & AB981663 & \\
\hline 45. & Lao3 & & 2011 & & AB981666 & \\
\hline
\end{tabular}




\begin{tabular}{|c|c|c|c|c|c|c|}
\hline 46. & Lao4 & & 2011 & & AB981664 & \\
\hline 47. & Lao5 & & 2011 & & AB981667 & \\
\hline 48. & $\mathrm{Lao} 7$ & & 2011 & & AB981668 & \\
\hline 49. & Lao8 & & 2011 & & AB981669 & \\
\hline 50. & Lao10 & & 2011 & & AB981670 & \\
\hline 51. & Lao11 & & 2012 & & AB981671 & \\
\hline 52. & Lao12 & & 2012 & & AB981672 & \\
\hline 53. & Lao13 & & 2012 & & AB981673 & \\
\hline 54. & Lao17 & & 2012 & & AB981674 & \\
\hline 55. & Lao21 & & 2012 & & AB981675 & \\
\hline 56. & Lao22 & & 2012 & & AB981676 & \\
\hline 57. & Lao23 & & 2012 & & AB981677 & \\
\hline 58. & 9337SWI & Switzerland & 1993 & bat & GU992316 & $\begin{array}{l}\text { Vandekerkhove et al., } \\
\text { direct submission }\end{array}$ \\
\hline 59. & PV & \multicolumn{3}{|c|}{ France, Vaccine strain } & M13215 & Tordo et al., 1986 \\
\hline
\end{tabular}

